\title{
PROVIDING THE CORPORATE SECURITY STRATEGY IN THE MANAGEMENT SYSTEM OF THE ENTERPRISE
}

\author{
Taras SHYRA (1) ${ }^{*}$, Oleksandr SHTYROV (i) 2 , Ivan KORCHYNSKYY (D) 3 , \\ Anastasiia ZERKAL (1) ${ }^{4}$, Halyna SKORYK (D) 5 \\ ${ }^{1}$ Faculty of Media Communications and Entrepreneurship, Ukrainian Academy of Printing, Lviv, Ukraine \\ ${ }^{2}$ Institute of Public Administration, Petro Mohyla Black Sea National University, Mykolaiv, Ukraine \\ ${ }^{3}$ Department of Finance and Accounting, Lviv State University of Internal Affairs, Lviv, Ukraine \\ ${ }^{4}$ Finance, Accounting and Taxation Department, Classic Private University, Zaporizhzhya, Ukraine \\ ${ }^{5}$ Department of Theoretical and Applied Economics, Lviv Polytechnic National University, Lviv, Ukraine
}

Received 16 June 2020; accepted 5 August 2020

\begin{abstract}
Three basic variants of the strategy for ensuring corporate security of an industrial enterprise ("survival", "stabilization" and "support") are proposed, the choice of one of which is associated with the results of assessing the level of corporate security. By applying the hierarchy analysis method for one of the studied enterprises, threats were identified that can have the most significant impact on the implementation of the basic strategy, therefore, they require the use of appropriate tactical countermeasures and make it possible to achieve strategic goals. Article theoretically generalizes and resolves the scientific and practical problem, which consists in developing the theoretical and methodological foundations for ensuring corporate security in the context of countering external and internal threats. In the process of research, methods of expert evaluation were used, as well as hierarchical ordering methodologies together with the use of a matrix of pairwise comparisons. It is substantiated that in conditions of high dynamics of changes in the environment of enterprise functioning, there is a need to predict changes in the influence of threats (strengthening, unchanged, weakening), combined into the groups "internal" and "external". The calculations carried out provided the formation of the necessary information basis for planning and implementing tactical protective measures based on the increased influence in the conditions of the functioning of enterprises in Eastern Europe, these are precisely internal threats. The value of this study lies in the fact that such a system for assessing external and internal threats that affect the corporate security of industrial enterprises will allow to quickly and efficiently form a system to counter the impact of these threats.
\end{abstract}

Keywords: corporate security, threat, enterprise, matrix of paired comparisons, scenario, hierarchy.

JEL Classification: M14, G34, P42, L21.

\section{Introduction}

The problem of ensuring the security of an enterprise has become especially acute in the last two decades, to the greatest extent caused by transformational changes in the world and national economies and the formation of a sector of non-state-owned enterprises. The owner, and not only government agencies, should take care of the formation of safe conditions for the functioning and development of a certain business entity, requires the development of an appropriate scientific justification based on the actual conditions of doing business in a particular country (Calder, 2016).

The priority of forming the methodological basis for ensuring corporate security of enterprises today is determined primarily by two key circumstances. Firstly, the need to create safe conditions for development for each business entity determines the riskiness of entrepreneurial activity in general and the difficult business environment due to the length of transformation processes and instability in the national economy. Secondly, the importance of the role of the corporations that are functioning today, which they already play in the economic processes of our country and the growth of their influence, by analogy with other countries, in the future (McKenzie-Skene, 2019).

It can be argued that corporate security is a broader concept than the concept of "security" and "economic security", because it determines the need to perform a wide range of tasks. These tasks include monitoring the

*Corresponding author. E-mail: education_univer21@yhaoo.com 
production process and sales of products to identify unused opportunities with a subsequent increase in the efficiency of using available corporate resources; formation of the necessary information basis for making tactical and strategic decisions by managers of all levels, taking into account the security aspect, including based on the results of business intelligence; protection of the information field of the enterprise, in particular, trade secrets; ensuring physical protection of the corporation's property and preventing and suppressing internal conflicts between groups of employees; work with job applicants and corporation personnel to improve the motivation system and efficient use of the personal potential of each employee; protection of corporate rights of participants; prevention and elimination of contradictions between the interests of managers and shareholders, etc (Mukherjee, 2019).

Summarizing, it is advisable to emphasize once again that ensuring the sustainable development of enterprises in conditions of high unpredictable changes in the operating environment is possible only if due attention is paid to the problem of security, in particular corporate security.

The importance of ensuring corporate security is becoming a priority not only for joint-stock companies, but also for other forms of entrepreneurial activity, in accordance with generally accepted world practice, can be attributed to corporations, and this, as already noted above, limited liability companies, additional liability companies and production cooperatives. The basis of this thesis is that in these enterprises there are internal conflicts between participants and managers, between individual participants and groups of workers, the enterprise and local authorities and society, etc., which are traditionally not considered in the process of ensuring economic security (Sadok et al., 2020).

The existing practice of ensuring corporate security is focused on solving current problems, that is, identifying losses of the financial and economic activities of the enterprise and property losses with the aim of eliminating them and preventing them in the future. In fact, this is a solution to the most complex current problems, it does not contribute to the formation of safe conditions in the medium and long term (Frey et al., 2019).

Stabilization of the functioning of industrial enterprises requires the development and application of a corporate security strategy that would be closely linked to the economic development strategy of the enterprise and formulate a clear plan for the implementation of protective measures with an appropriate allocation of resource and organizational support (Sitdikova \& Starodumova, 2019)

The formation of a corporate security system is a lengthy process with the phased implementation of procedures related to the transformation of the existing organizational structure and the redistribution of resource support. The functioning of the corporate security system requires clarity in the actions of security entities, in particular in the development and implementation of protective measures (Semenyutina, 2018).
Our goal is to identify the main approaches to the selection and implementation of a flexible strategy for ensuring corporate security of industrial enterprises.

The basis for the proposed concept of a strategy for ensuring corporate security of an enterprise is the base term strategy. In the field of management, the term strategy began to be used only in the 1920s. At the first stages, it was only a resource management strategy, with a subsequent reorientation to the timely formation of conditions for a quick response to a possible change in the influence of the external environment (Hardman, 2018).

\section{Literature review}

Scientists paid a lot of attention to ensuring the safety of enterprises, in particular Abalkin (2019), Anilovska (2020), Sylkin et al. (2019), Shtangret (2019) and others. Theoretical research has shown that the issue of assessing threats to corporate attention is not given due attention. In some publications, the authors are limited to a list of possible threats, without highlighting the level of their impact (Berle \& Means, 1997).

The search and selection of the optimal strategy for corporate security and the development of its culture can be found in various scientific materials of scientists. Someone (Szczepanska-Woszczyna, 2018; Schatz \& Bashroush, 2018; Kryshtanovych et al., 2020) seek to combine a general development strategy with corporate culture. However, our study, even in the context of a general development strategy, suggests a conceptual approach contributes to the achievement of strategic goals by improving the flexibility of the process of implementing the basic strategy through the timely application of tactical protective measures. Others (Badr et al., 2011; Orlyk, 2016) are looking at new opportunities to integrate existing corporate security strategies into business processes. However, our research justifies the need to pay attention to the process of implementing a certain strategy, which is determined by the configuration of the influence of the main internal and external threats and requires the timely implementation of corrective tactical measures.

The analysis revealed the presence of excellent points of view on the essence of the strategy (Shyra, 2019). For the needs of this study, it is advisable to focus only on some of them, which in the future will form the basis for the interpretation of the concept of a corporate security strategy for an enterprise. The first approach defines strategy as a means of achieving goals. The foundations of this approach were laid back by Chandler (1962), who presented the strategy as defining the main long-term goals and objectives of the enterprise, determining the course of action and the allocation of resources needed to achieve them.

According to the second approach, a strategy is an established sequence of actions. Such a point of view, for example, was held by Karlof (1989), in whose exchange strategy "a generalized model of the actions necessary to 
achieve the goals by coordinating and allocating company resources". A third approach links strategies to decision making. This approach is clearly traced in the scientific legacy of Ansoff (2005), who defines the strategy as one of several sets of rules for making decisions about the behavior of an organization in conditions of incomplete information about the future development of the enterprise. Also, mention should be made (Ansoff et al., 2019) of research into the use of weak signals in the field of strategic management. Our study covers more the impact of threats on the sphere of strategic management.

We can distinguish a certain integrated approach, which not only combines the individual elements of other approaches, but significantly expands the scope of the strategy, taking into account the internal parameters of the functioning of the enterprise, changing the external environment, contributes to the interests of participants in economic relations.

So, Tulenkov (2019) defines a strategy as a set of norms, guidelines, directions, areas, methods and rules of activity that establish the growth and high competitiveness of an organization, which strengthen the position in the market and increase the ability to survive in a competitive environment.

Ludbey et al. (2018) in their work studied the features of the level structure of corporate security, while an important element of their research was the study of the role of the human factor in these processes.

Summarizing, it can be argued that the synthesis of these approaches forms an idea of strategy as a model that, being tied to the actual conditions of the enterprise, ensures the achievement of goals by implementing a certain clearly justified sequence of actions. A scientific search revealed that the issue of corporate security was not given due attention.

\section{Research model}

It is advisable to emphasize that the strategy is not considered in the field of corporate security, because today the actions of security entities are focused on eliminating the consequences of the negative impact of internal and external threats, stabilizing the situation, protecting property and preserving the business in the short term. Despite this, it is advisable to identify key methodological foundations for developing a corporate security strategy for an enterprise (Sylkin et al., 2018):

The corporate security strategy should be utilized with the enterprise development strategy. Coordination consists in taking into account the strategy for the development of security aspects, and the strategy for ensuring corporate security should include measures to create a safe environment for the development of the enterprise;

The corporate security strategy should be based on the actual level of corporate security, the availability of resource and organizational support that can be used to develop and implement protective measures;
The corporate security strategy should be flexible. Change of strategy is carried out according to the results of assessment of the impact of key external and internal threats;

To solve the problem of the lack of reliable information on changes in the functioning environment in the long term, it is advisable to use forecasts.

Thus, the corporate security strategy for the enterprise can be interpreted as a tool for creating safe conditions for implementing the enterprise development strategy; it implies the achievement of corporate interests through the fulfillment of tasks within the enterprise corporate security system, taking into account the actual level of corporate security and possible changes in the impact of key internal and external threats. We detail the essence of the proposed definition. In accordance with the actual level of corporate security (the calculated value of the integral indicator), three options are proposed for the strategy of ensuring corporate security of an industrial enterprise (Table 1).

Table 1. Strategies for ensuring corporate security of the industrial enterprise (developed by the author)

\begin{tabular}{|l|l|l|}
\hline $\begin{array}{c}\text { Security } \\
\text { level }\end{array}$ & $\begin{array}{c}\text { Strategy } \\
\text { option }\end{array}$ & \multicolumn{1}{|c|}{ Key Features } \\
\hline Low & Survival & $\begin{array}{l}\text { Adaptation to business conditions, } \\
\text { concentration of security subjects on } \\
\text { preserving property, protecting corporate } \\
\text { interests, efficient use of corporate } \\
\text { resources, maintaining enterprise viability }\end{array}$ \\
\hline Average & $\begin{array}{l}\text { Stabi- } \\
\text { lization }\end{array}$ & $\begin{array}{l}\text { Implementation of changes aimed at } \\
\text { restoring the stability and stability of } \\
\text { the financial and economic activities } \\
\text { of the enterprise, increasing the level } \\
\text { of security and creating safe conditions } \\
\text { for achieving corporate interests }\end{array}$ \\
\hline High & $\begin{array}{l}\text { Suppor- } \\
\text { ting }\end{array}$ & $\begin{array}{l}\text { Maintaining the achieved security level, } \\
\text { monitoring the level of impact of internal } \\
\text { and external threats, creating reserves }\end{array}$ \\
\hline
\end{tabular}

The survival strategy is used in conditions of economic crisis, instability, high inflation, or when goods are in a saturation stage and consists in trying to adapt to difficult market conditions and the current situation. This strategy is resorted to when the financial and economic indicators of the enterprise enter into a steady downward trend, when the very existence of the enterprise is threatened for various reasons.

The stabilization strategy is used by enterprises that already occupy a strong position in the market, that is, in conditions of stable sales volumes and income received, and is carried out in order to maintain the existing state for as long as possible. This strategy is used as a basic corporate strategy by enterprises located in industries with stable technology, and the owners and managers are generally satisfied with the state of their enterprise.

The supporting strategy is used by the enterprise if it has achieved its safety targets and it seeks to maintain the already existing level of achievements. 
Unstable business conditions require concentration not only on the choice of a specific strategy, but also on ensuring its implementation (Sylkin et al., 2019).

The conditions for doing business for most industrial enterprises can be considered not only difficult, but are more associated with a quick and unpredictable change in the operating environment. To implement the enterprise development strategy, safe conditions are necessary, the achievement of which requires the development and application of a corporate security strategy. The basis for choosing one of the possible strategy options is the results of corporate security assessment with subsequent adjustment due to the systematic identification and hierarchical ordering of key external and internal threats. Therefore, our study is aimed at creating a conceptual approach to developing tactics of actions of security entities, as the basis for maintaining the implementation of the strategy, based on the available resource and organizational support for corporate security of an industrial enterprise.

To solve the problem before us, we applied the hierarchy analysis method (Saati, 2019), which is also used to solve economic problems. This method is conveniently used to construct possible future scenarios and make managerial decisions (Zgurovsky \& Pankratova, 2020).

The specialists involved in the assessment alternately pairwise select the selected objects among themselves. A feature of the applied method is that objects whose behavior does not have accurate numerical estimates are compared. With this comparison, the least important object is a unit, and the more important object consists of such units. In other words, pairwise comparisons make it possible to obtain more accurate characteristics of objects (their weights) in contrast to a simple definition of what is more important and what is less important for a number of compared objects.
By systematizing the opinions of experts on external and internal threats that affect the corporate security of industrial enterprises, we highlighted the main ones ( $\mathrm{Ta}-$ ble 2).

Table 2. The key threats to corporate security of industrial enterprises (developed by the author)

\begin{tabular}{|c|c|}
\hline \multirow{4}{*}{$\begin{array}{l}\text { Inter- } \\
\text { nal } \\
\text { Threats }\end{array}$} & $\begin{array}{l}\text { Corporate conflicts between shareholders and ma- } \\
\text { nagers, majorities and minority shareholders (CC) }\end{array}$ \\
\hline & $\begin{array}{l}\text { Inadequate corporate performance due to low } \\
\text { managerial performance (ICP) }\end{array}$ \\
\hline & $\begin{array}{l}\text { A high degree of physical and moral depreciation of } \\
\text { fixed assets (DFA) }\end{array}$ \\
\hline & $\begin{array}{l}\text { Inadequate qualifications (deficit) of personnel } \\
\text { (QDP) }\end{array}$ \\
\hline \multirow{4}{*}{$\begin{array}{l}\text { Exter- } \\
\text { nal } \\
\text { Threats }\end{array}$} & High level of dependence on bank loans (DBL) \\
\hline & $\begin{array}{l}\text { Political instability and complex transformation } \\
\text { processes in the economy (PI) }\end{array}$ \\
\hline & Increased competition from foreign producers (IC) \\
\hline & $\begin{array}{l}\text { Decrease in well-being of the population and } \\
\text { purchasing power of consumers (DWP) }\end{array}$ \\
\hline
\end{tabular}

We now turn to the direct determination of the strategy for ensuring corporate security of the enterprise and the determination of the necessary tactical measures for its implementation in accordance with the changing influence of the main internal and external threats. It is necessary to solve the problem in accordance with the hierarchy (Figure 1). All presented external and internal threats can increase or decrease in different periods of time and due to changes in conditions. Depending on whether they are

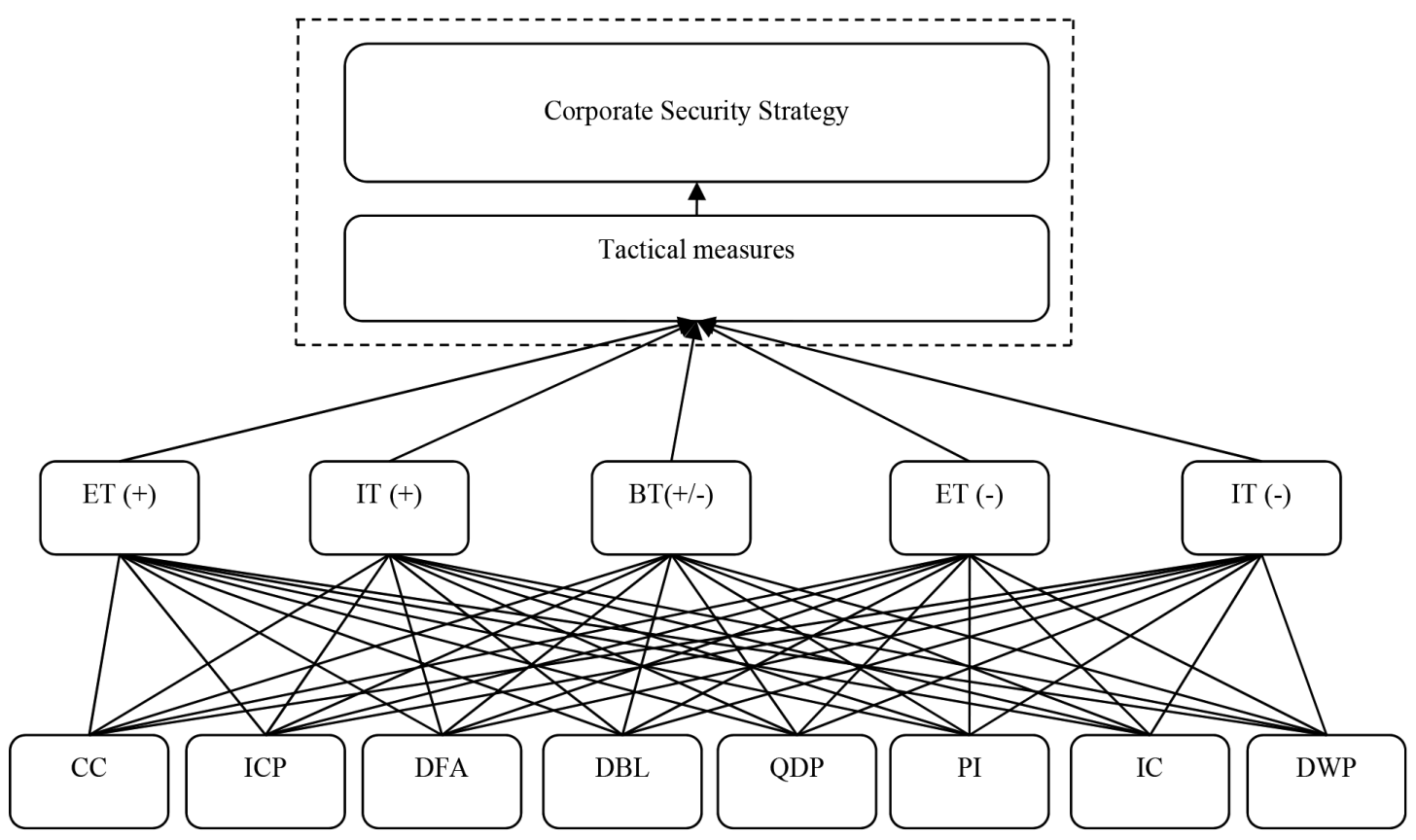

Figure 1. Modeling the implementation of the corporate security strategy for an industrial enterprise by hierarchically streamlining changes in the impact of key threats (developed by the author) 
strengthened or weakened, the enterprise, according to our study, must make a decision on the implementation of certain measures, in Figure 1 corresponds to the vector of arrows presented by the measures.

ET $(+)$ represents external threat amplification. IT $(+)$ represents threat amplification. BT (+/-) provides for strengthening or weakening basic threats. ET (-) represents external threat mitigation. IT (-) means weakening internal threats.

The pinnacle of this model is the goal - "Implementation of a corporate security strategy for an enterprise". The second level of this hierarchy is formed by cases of changes in the impact of threats to corporate security of industrial enterprises (criteria). At the third level are threats, described in more detail above, most significantly affect the actual level of corporate security, and their change requires attention in terms of the possibility of achieving strategic goals. To illustrate the presentation of the results, we have chosen industrial enterprises in Eastern Europe, in particular Ukraine and Poland.

Table 3. Matrix of paired comparisons of alternative scenarios (developed by the author)

\begin{tabular}{|c|c|c|c|c|c|}
\hline & $\mathrm{ET}(+)$ & $\mathrm{IT}(+)$ & $\mathrm{BT}$ & $\mathrm{ET}(-)$ & $\mathrm{IT}(-)$ \\
\hline $\mathrm{ET}(+)$ & 1 & 1 & 1 & 1 & 5 \\
\hline $\mathrm{IT}(+)$ & 1 & 1 & 1 & 1 & 1 \\
\hline $\mathrm{BT}$ & 1 & 1 & 1 & 1 & 1 \\
\hline $\mathrm{ET}(-)$ & 1 & 1 & 1 & 1 & 2 \\
\hline $\mathrm{IT}(-)$ & $1 / 5$ & 1 & 1 & $1 / 2$ & 1 \\
\hline
\end{tabular}

The specialists (experts) involved in the assessment consistently pairwise compare the significance of changes in the impact of threats to corporate security of an industrial enterprise. Comparison of changes in the impact of threats with each other occurs on the following scale (Table 4):

Table 4. Scale of relative importance of comparison objects (developed by the author)

\begin{tabular}{|c|l|}
\hline $\begin{array}{c}\text { Assessment, } \\
\text { points }\end{array}$ & \multicolumn{1}{|c|}{ Assistance in choosing an assessment } \\
\hline 1 & Comparison objects are equivalent \\
\hline 3 & One object slightly dominates the other \\
\hline 5 & One object dominates another object \\
\hline 7 & One object is vastly superior to another \\
\hline 9 & One object absolutely dominates the other \\
\hline
\end{tabular}

Table 5 compare the changes in the influence of the threat "reduction in the welfare of the population and the purchasing power of consumers" on ensuring the corporate security of an industrial enterprise (first ET $(+)$ with IT $(+)$, then ET $(+)$ with BT, then ET $(+)$ with ET(-) etc.). In the process of summarizing the opinions of specialists (experts), the person making the decision, the Table 5 is filled.
Table 5. Matrix of pairwise comparisons of alternative scenarios for the development of the situation (developed by the author)

\begin{tabular}{|c|c|c|c|c|c|}
\hline & $\mathrm{ET}(+)$ & $\mathrm{IT}(+)$ & $\mathrm{BT}$ & $\mathrm{ET}(-)$ & $\mathrm{IT}(-)$ \\
\hline $\mathrm{ET}(+)$ & 1 & & & & \\
\hline $\mathrm{IT}(+)$ & & 1 & & & \\
\hline $\mathrm{BT}$ & & & 1 & & \\
\hline $\mathrm{ET}(-)$ & & & & 1 & \\
\hline $\mathrm{IT}(-)$ & & & & & 1 \\
\hline
\end{tabular}

Filling in the Table 5 is as follows: for two objects, they are compared with each other, depending on their importance and the degree of influence on the situation under consideration, to have the value of the corresponding element of Table 1 on the scale of relative importance of objects of comparison. Table 5. Diagonal elements of the table are equal to one. The lower part of the table is filled with the opposite values. If there are minor differences between the weights of objects, you can also use the paired numbers 2, 4, 6 and 8 and their inverse values.

The results obtained are processed using a computer program (listing, which we will provide additionally, if necessary). In this case, in Table 6 we see the significance of the influence of the change in the influence of the threat "decrease in the well-being of the population and the purchasing power of consumers" on ensuring the corporate security of an industrial enterprise, where $w_{i}$ is the change in the influence of threats, and $S_{j}$ is their weight calculated using the computer program discussed above.

\section{Results and discussion}

The first step is to evaluate alternative scenarios. The specialists involved in the assessment need to make comparisons, where $\mathrm{n}$ is the number of criteria at one level. In our case, five cases of changes in the impact of threats to corporate security of industrial enterprises, respectively, it is necessary to conduct 10 comparisons of different pairs of these changes. For the study, 10 leading industrial enterprises of Eastern Europe were taken from such countries as the Czech Republic, Poland and Ukraine. The reason for choosing enterprises in these particular countries is that, in general terms, their specifics of functioning and the conditions for running the economy are similar. In addition, over the years, the enterprises of these countries have formed strong working relationships with each other, which allowed them to form strong channels for exchange of experience. Since the determination of the indicators we study is a subjective process, their research is a difficult process, therefore, the fact that enterprises in these countries easily got in touch and were interested in further adaptation of the results obtained was another reason for the selection of enterprises in these countries. Data collection from these enterprises was carried out remotely, taking into account the existing unstable epidemic situation. The management 
of the enterprises asked not to indicate the data of the institutions participating in the study. Further active application of the proposed methodology was carried out in the practice of the functioning of an operating industrial enterprise with branches both in Poland and in Ukraine.

When constructing a matrix of paired comparisons of cases of changes in the impact of threats to corporate security of industrial enterprises, they were compared in pairs with respect to the common goal - the implementation of the strategy for ensuring corporate security of the enterprise (Table 3). The sums of the elements of the columns of the pairwise threat comparison matrix are shown in Table 6.

Table 6. Sum of column elements of the matrix of paired comparisons scenarios (developed by the author)

\begin{tabular}{|c|c|c|c|c|c|}
\hline$w_{i}$ & $w_{1}$ & $w_{2}$ & $w_{3}$ & $w_{4}$ & $w_{5}$ \\
\hline$S_{j}$ & 0.267 & 0.196 & 0.193 & 0.222 & 0.122 \\
\hline
\end{tabular}

The next step in our study will be to calculate the level of inconsistency of the matrix of pairwise comparisons.

Table 7. Determining the inconsistency level of the matrix of pairwise comparisons (developed by the author)

\begin{tabular}{|l|c|c|c|}
\hline Indicator & $\begin{array}{c}\text { Largest eigen- } \\
\text { value, } k_{\max }\end{array}$ & $\begin{array}{c}\text { Coefficient of } \\
\text { consistency, } C I\end{array}$ & $\begin{array}{c}\text { The level of in- } \\
\text { consistency, CR }\end{array}$ \\
\hline Results & 5.289 & 0.072 & 0.064 \\
\hline
\end{tabular}

The calculations were carried out correctly, since the value of the largest eigenvalue $k_{\max }$, the mismatch coefficient, $C I$ and the inconsistency level, $C R$ are within normal limits (Table 7).

The second step is to compare alternative scenarios. Since the hierarchy contains eight main threats and five options for changing influence, it is necessary to draw $n \times \frac{m \times(m-1)}{2}$, where $m-$ is the number of alternatives, that is, 140 options for the development of the situation must be compared.

Development options (alternative development scenarios) are compared for each of the criteria. In this case,

Table 8. Matrix of pairwise comparisons of threats to corporate security with increasing influence of external threats (developed by the author)

\begin{tabular}{|c|c|c|c|c|c|c|c|c|}
\hline ET(+) & CC & ICP & DFA & QDP & DBL & PI & IC & DWP \\
\hline CC & 1 & 1 & 2 & 1 & 4 & $1 / 3$ & $1 / 2$ & 4 \\
\hline ICP & 1 & 1 & 1 & 1 & 1 & $1 / 4$ & $1 / 3$ & 5 \\
\hline DFA & $1 / 2$ & 1 & 1 & 1 & 1 & $1 / 6$ & 2 & 7 \\
\hline QDP & 1 & 1 & 1 & 1 & 1 & $1 / 5$ & $1 / 4$ & 4 \\
\hline DBL & $1 / 4$ & 1 & 1 & 2 & 1 & $1 / 7$ & $1 / 6$ & 8 \\
\hline PI & 3 & 4 & 6 & 5 & 7 & 1 & 3 & 6 \\
\hline IC & 2 & 3 & $1 / 2$ & 4 & 6 & $1 / 3$ & 1 & 5 \\
\hline DWP & $1 / 4$ & $1 / 5$ & $1 / 7$ & $1 / 4$ & $1 / 8$ & $1 / 6$ & $1 / 5$ & 1 \\
\hline
\end{tabular}

there is only one level of criteria, so there is a pairwise comparison of alternatives for each of the eight criteria. The calculations were performed using a specific computer program of hierarchical ordering (Table 8, 11, 14, 17, 20) The main goal of the proposed program is to conduct simulation (computer) modeling in systems analysis by binary comparisons.

Once we have formed a matrix of paired comparisons of threats to corporate security in the case of modeling the increase in the impact of external threats, the next step will be to calculate the sum of the elements of this matrix, which can be used to determine the level of inconsistency of the matrix of pairwise comparisons (Table 9-10).

Table 9. The sum of the elements of the columns of the matrix of pairwise comparisons (developed by the author)

\begin{tabular}{|c|c|c|c|c|c|c|c|c|}
\hline$u_{1 j}$ & $u_{11}$ & $u_{12}$ & $u_{13}$ & $u_{14}$ & $u_{15}$ & $u_{16}$ & $u_{17}$ & $u_{18}$ \\
\hline$S_{j}$ & 0.117 & 0.085 & 0.096 & 0.077 & 0.064 & 0.368 & 0.172 & 0.021 \\
\hline
\end{tabular}

Table 10. Determining the inconsistency level of the matrix of pairwise comparisons (developed by the author)

\begin{tabular}{|l|c|c|c|}
\hline Indicator & $\begin{array}{c}\text { Largest eigen- } \\
\text { value, } k_{\max }\end{array}$ & $\begin{array}{c}\text { Coefficient of } \\
\text { consistency, CI }\end{array}$ & $\begin{array}{c}\text { The level of in- } \\
\text { consistency, CR }\end{array}$ \\
\hline Results & 8.986 & 0.141 & 0.099 \\
\hline
\end{tabular}

In the same way the investigated indicators for internal threats are calculated (Table 11).

Table 11. Matrix of pairwise comparisons of threats to corporate security with increasing influence of internal threats (developed by the author)

\begin{tabular}{|c|c|c|c|c|c|c|c|c|}
\hline IT(+) & CC & ICP & DFA & QDP & DBL & PI & IC & DWP \\
\hline CC & 1 & 2 & 3 & 7 & 4 & 5 & 8 & 9 \\
\hline ICP & $1 / 2$ & 1 & 2 & 6 & 3 & 4 & 7 & 8 \\
\hline DFA & $1 / 3$ & $1 / 2$ & 1 & 5 & 1 & 3 & 6 & 7 \\
\hline QDP & $1 / 7$ & $1 / 6$ & $1 / 5$ & 1 & 1 & 1 & 2 & 3 \\
\hline DBL & $1 / 4$ & $1 / 3$ & 1 & 1 & 1 & 2 & 5 & 6 \\
\hline PI & $1 / 5$ & $1 / 4$ & $1 / 3$ & 1 & $1 / 2$ & 1 & 4 & 5 \\
\hline IC & $1 / 8$ & $1 / 7$ & $1 / 6$ & $1 / 2$ & $1 / 5$ & $1 / 4$ & 1 & 4 \\
\hline DWP & $1 / 9$ & $1 / 8$ & $1 / 7$ & $1 / 3$ & $1 / 6$ & $1 / 5$ & $1 / 4$ & 1 \\
\hline
\end{tabular}

After the formation of the matrix of paired comparisons of threats to corporate security in the case of simulating the increased impact of internal threats, the next step is to calculate the sum of the elements of this matrix, which can be used to determine the level of inconsistency of the matrix of paired comparisons (Table 12-14).

Table 12. The sum of the elements of the columns of the matrix of pairwise comparisons (developed by the author)

\begin{tabular}{|c|c|c|c|c|c|c|c|c|}
\hline$u_{2 j}$ & $u_{21}$ & $u_{22}$ & $u_{23}$ & $u_{24}$ & $u_{25}$ & $u_{26}$ & $u_{27}$ & $u_{28}$ \\
\hline$S_{j}$ & 0.339 & 0.238 & 0.151 & 0.054 & 0.103 & 0.067 & 0.030 & 0.018 \\
\hline
\end{tabular}


Table 13. Determining the inconsistency level of the matrix of pairwise comparisons (developed by the author)

\begin{tabular}{|l|c|c|c|}
\hline Indicator & $\begin{array}{c}\text { Largest eigen- } \\
\text { value, } k_{\max }\end{array}$ & $\begin{array}{c}\text { Coefficient of } \\
\text { consistency, } C I\end{array}$ & $\begin{array}{c}\text { The level of in- } \\
\text { consistency, } C R\end{array}$ \\
\hline Results & 8.505 & 0.072 & 0.051 \\
\hline
\end{tabular}

Table 14. Matrix of paired comparisons of threats to corporate security with the constant impact of external and internal threats (developed by the author)

\begin{tabular}{|c|c|c|c|c|c|c|c|c|}
\hline BT & CC & ICP & DFA & QDP & DBL & PI & IC & DWP \\
\hline CC & 1 & 2 & 4 & 3 & 5 & 7 & 6 & 8 \\
\hline ICP & $1 / 2$ & 1 & 3 & 6 & 4 & 2 & 5 & 5 \\
\hline DFA & $1 / 4$ & $1 / 3$ & 1 & 4 & 2 & 2 & 3 & 3 \\
\hline QDP & $1 / 3$ & $1 / 6$ & $1 / 4$ & 1 & $1 / 3$ & $1 / 5$ & 2 & 1 \\
\hline DBL & $1 / 5$ & $1 / 4$ & $1 / 2$ & 3 & 1 & $1 / 3$ & 2 & 2 \\
\hline PI & $1 / 7$ & $1 / 2$ & $1 / 2$ & 5 & 3 & 1 & 4 & 4 \\
\hline IC & $1 / 6$ & $1 / 5$ & $1 / 3$ & $1 / 2$ & $1 / 2$ & $1 / 4$ & 1 & 1 \\
\hline DWP & $1 / 8$ & $1 / 5$ & $1 / 3$ & 1 & $1 / 2$ & $1 / 4$ & 1 & 1 \\
\hline
\end{tabular}

After we have built a matrix of paired comparisons of threats to corporate security in the case of modelling the constant impact of internal and external threats, the next step is to calculate the sum of the elements of this matrix, which can be used to determine a target indicator such as the level of inconsistency of the paired comparison matrix (Table 15-22).

Table 15. The sum of the elements of the columns of the matrix of pairwise comparisons (developed by the author)

\begin{tabular}{|c|c|c|c|c|c|c|c|c|}
\hline$u_{3 j}$ & $u_{31}$ & $u_{32}$ & $u_{33}$ & $u_{34}$ & $u_{35}$ & $u_{36}$ & $u_{37}$ & $u_{38}$ \\
\hline$S_{j}$ & 0.345 & 0.231 & 0.123 & 0.041 & 0.068 & 0.118 & 0.036 & 0.038 \\
\hline
\end{tabular}

Table 16. Determining the inconsistency level of the matrix of pairwise comparisons (developed by the author)

\begin{tabular}{|l|c|c|c|}
\hline Indicator & $\begin{array}{c}\text { Largest eigen- } \\
\text { value, } k_{\max }\end{array}$ & $\begin{array}{c}\text { Coefficient of } \\
\text { consistency, } C I\end{array}$ & $\begin{array}{c}\text { The level of in- } \\
\text { consistency, } C R\end{array}$ \\
\hline Results & 8.596 & 0.0856 & 0.060 \\
\hline
\end{tabular}

Table 17. Matrix of paired comparisons of corporate security threats while mitigating the impact of external threats (developed by the author)

\begin{tabular}{|c|c|c|c|c|c|c|c|c|}
\hline ET(-) & CC & ICP & DFA & QDP & DBL & PI & IC & DWP \\
\hline CC & 1 & 1 & 2 & 1 & 3 & $1 / 2$ & 1 & 3 \\
\hline ICP & 1 & 1 & 1 & 1 & 2 & $1 / 3$ & $1 / 2$ & 4 \\
\hline DFA & $1 / 2$ & 1 & 1 & 2 & 1 & $1 / 5$ & 1 & 6 \\
\hline QDP & 1 & 1 & $1 / 2$ & 1 & 4 & $1 / 4$ & $1 / 3$ & 3 \\
\hline DBL & $1 / 3$ & $1 / 2$ & 1 & $1 / 4$ & 1 & $1 / 6$ & $1 / 5$ & 7 \\
\hline PI & 2 & 3 & 5 & 4 & 6 & 1 & 2 & 5 \\
\hline IC & 1 & 2 & 1 & 3 & 5 & $1 / 2$ & 1 & 4 \\
\hline DWP & $1 / 3$ & $1 / 4$ & $1 / 6$ & $1 / 3$ & $1 / 7$ & $1 / 5$ & $1 / 4$ & 1 \\
\hline
\end{tabular}

Table 18. The sum of the elements of the columns of the matrix of pairwise comparisons (developed by the author)

\begin{tabular}{|c|c|c|c|c|c|c|c|c|}
\hline$u_{4 j}$ & $u_{41}$ & $u_{42}$ & $u_{43}$ & $u_{44}$ & $u_{45}$ & $u_{46}$ & $u_{47}$ & $u_{48}$ \\
\hline$S_{j}$ & 0.133 & 0.105 & 0.104 & 0.093 & 0.056 & 0.312 & 0.169 & 0.028 \\
\hline
\end{tabular}

In the same way as such indicators were calculated above, we calculated the level of inconsistency of the matrix of pairwise comparisons

Table 19. Determining the inconsistency level of the matrix of pairwise comparisons (developed by the author)

\begin{tabular}{|l|c|c|c|}
\hline Indicator & $\begin{array}{c}\text { Largest eigen- } \\
\text { value, } k_{\max }\end{array}$ & $\begin{array}{c}\text { Coefficient of } \\
\text { consistency, } C I\end{array}$ & $\begin{array}{c}\text { The level of in- } \\
\text { consistency, } C R\end{array}$ \\
\hline Results & 8.789 & 0.113 & 0.080 \\
\hline
\end{tabular}

Table 20. Matrix of paired comparisons of corporate security threats while mitigating the impact of threats

(developed by the author)

\begin{tabular}{|c|c|c|c|c|c|c|c|c|}
\hline IT(-) & CC & ICP & DFA & QDP & DBL & PI & IC & DWP \\
\hline CC & 1 & 1 & 1 & 4 & 1 & 2 & 5 & 6 \\
\hline ICP & 1 & 1 & 1 & 3 & 1 & 1 & 4 & 5 \\
\hline DFA & 1 & 1 & 1 & 2 & 1 & 1 & 3 & 4 \\
\hline QDP & $1 / 4$ & $1 / 3$ & $1 / 2$ & 1 & 1 & 1 & 1 & 1 \\
\hline DBL & 1 & 1 & 1 & 1 & 1 & 1 & 2 & 5 \\
\hline PI & $1 / 2$ & 1 & 1 & 1 & 1 & 1 & 1 & 2 \\
\hline IC & $1 / 5$ & $1 / 4$ & $1 / 3$ & 1 & $1 / 2$ & 1 & 1 & 1 \\
\hline DWP & $1 / 6$ & $1 / 5$ & $1 / 4$ & 1 & $1 / 5$ & $1 / 2$ & 1 & 1 \\
\hline
\end{tabular}

Table 21. The sum of the elements of the columns of the matrix of pairwise comparisons (developed by the author)

\begin{tabular}{|c|c|c|c|c|c|c|c|c|}
\hline$u_{5 j}$ & $u_{51}$ & $u_{52}$ & $u_{53}$ & $u_{54}$ & $u_{55}$ & $u_{56}$ & $u_{57}$ & $u_{58}$ \\
\hline$S_{j}$ & 0.221 & 0.183 & 0.163 & 0.073 & 0.146 & 0.109 & 0.060 & 0.045 \\
\hline
\end{tabular}

The last indicator that we will calculate will be the level the inconsistency level of the matrix of pairwise comparisons of corporate security threats while mitigating the impact of threats.

Table 22. Determining the inconsistency level of the matrix of pairwise comparisons (developed by the author)

\begin{tabular}{|l|c|c|c|}
\hline Indicator & $\begin{array}{l}\text { Largest eigen- } \\
\text { value, } k_{\max }\end{array}$ & $\begin{array}{l}\text { Coefficient of } \\
\text { consistency, } C I\end{array}$ & $\begin{array}{l}\text { The level of in- } \\
\text { consistency, CR }\end{array}$ \\
\hline Results & 8.369 & 0.053 & 0.037 \\
\hline
\end{tabular}

The calculations were carried out correctly, since the value of the largest eigenvalue $k_{\text {max }}$, the consistency coefficient, $C I$ and the level of disruption, $C R$ for each of the matrices (Table 8, 11, 14, 17, 20) are within normal limits (Table 10, 13, 16, 19, 22).

The third step is a synthesis of priorities. The degree of influence of a certain threat on the implementation of the selected strategy for ensuring corporate security of the 
enterprise (synthesis of priorities) $\mathrm{Ui}$ is established by the formula:

In accordance, we have the following system of equations for calculating priority values for all scenarios:

$U_{1}=w_{1} \times u_{11}+w_{2} \times u_{21}+w_{3} \times u_{31}+w_{4} \times u_{41}+w_{5} \times u_{51}$

$U_{2}=w_{1} \times u_{12}+w_{2} \times u_{22}+w_{3} \times u_{32}+w_{4} \times u_{42}+w_{5} \times u_{52} ;$

$U_{3}=w_{1} \times u_{13}+w_{2} \times u_{23}+w_{3} \times u_{33}+w_{4} \times u_{43}+w_{5} \times u_{53} ;$

$U_{4}=w_{1} \times u_{14}+w_{2} \times u_{24}+w_{3} \times u_{34}+w_{4} \times u_{44}+w_{5} \times u_{54}$

$U_{5}=w_{1} \times u_{15}+w_{2} \times u_{25}+w_{3} \times u_{35}+w_{4} \times u_{45}+w_{5} \times u_{5}$;

$U_{6}=w_{1} \times u_{16}+w_{2} \times u_{26}+w_{3} \times u_{36}+w_{4} \times u_{46}+w_{5} \times u_{56}$

$U_{7}=w_{1} \times u_{17}+w_{2} \times u_{27}+w_{3} \times u_{37}+w_{4} \times u_{47}+w_{5} \times u_{57} ;$

$U_{8}=w_{1} \times u_{18}+w_{2} \times u_{28}+w_{3} \times u_{38}+w_{4} \times u_{48}+w_{5} \times u_{58}$.

Substituting the corresponding values from Table 3,9 , $12,15,18,21$ in the system of equations (1) we obtain the following values of priorities for all scenarios considered:

$$
\begin{aligned}
& U_{1}=0.267 \times 0.117+0.196 \times 0.339+0.193 \times 0.345+ \\
& 0.222 \times 0.133+0.083 \times 0.221=0.220 ; \\
& U_{2}=0.267 \times 0.085+0.196 \times 0.238+0.193 \times 0.231+ \\
& 0.222 \times 0.105+0.122 \times 0.183=0.159 ; \\
& U_{3}=0.267 \times 0.096+0.196 \times 0.151+0.193 \times 0.123+ \\
& 0.222 \times 0.104+0.122 \times 0.163=0.122 ; \\
& U_{4}=0.267 \times 0.077+0.196 \times 0.054+0.193 \times 0.041+ \\
& 0.222 \times 0.093+0.122 \times 0.073=0.068 ;
\end{aligned}
$$$$
U_{5}=0.267 \times 0.064+0.196 \times 0.103+0.193 \times 0.068+
$$$$
0.222 \times 0.056+0.122 \times 0.146=0.080 \text {; }
$$$$
U_{6}=0.267 \times 0.368+0.196 \times 0.067+0.193 \times 0.118+
$$$$
0.222 \times 0.312+0.122 \times 0.109=0.216 \text {; }
$$$$
U_{7}=0.267 \times 0.172+0.196 \times 0.030+0.193 \times 0.036+
$$$$
0.222 \times 0.169+0.122 \times 0.060=0.105 \text {; }
$$$$
U_{8}=0.267 \times 0.021+0.196 \times 0.018+0.193 \times 0.038+
$$$$
0.222 \times 0.028+0.122 \times 0.045=0.029 \text {. }
$$

Interpretation of calculation results. The results obtained allow us to argue that in the conditions of the enterprise in Eastern Europe under consideration, the current level of security is low and is characterized by increased influence of external and internal threats, it requires the use of a survival strategy, which consists in adapting to the conditions of doing business, focusing security on the preservation of property, protection of corporate interests, more efficient use of corporate resources, support for the viability of the enterprise. Along with determining the general direction in the chosen version of the strategy, more important is the development of tactical measures that are required to achieve the task. In accordance with the calculations, tactical measures should be aimed at countering or adapting to the impact of threats for which Ui was maximum, and this:
$U_{1}$ - CC - corporate conflicts between shareholders and managers, majorities and minority shareholders;

$U_{6}$ - PI - political instability and complex transformation processes in the economy.

Accordingly, in determining the basic strategy, security actors should be focused on the implementation of tactical protective measures for the primary counteraction/adaptation to the action of each individual threat in the form of a possible change in their influence.

As a result, a conceptual approach to the selection and implementation of a strategy for ensuring corporate security of industrial enterprises was formulated, which consists in using the method of analysis of hierarchies to establish, according to the actual level of corporate security, the basic version of the strategy with subsequent adjustment of the implementation process in accordance with changes in the influence of external and internal threats, provides maximum flexibility in the implementation of protective measures to achieve strategic goals. The results obtained are certainly valuable, because they can significantly narrow the range of tasks of security actors in the implementation of a certain strategy, in particular by prioritizing a significantly limited range of threats.

\section{Conclusions}

By applying the method of hierarchy analysis for one of the studied enterprises in Eastern Europe, threats were identified that could have the most significant impact on the implementation of the basic strategy, therefore they require the use of appropriate tactical measures to counter and make it possible to achieve strategic goals. It is proved that in conditions of high dynamism of changes in the environment of the enterprise's functioning, there is a need to predict changes in the impact of threats (strengthening, without changes, weakening), combined into groups of "internal" and "external".

It turned out that at present, the security actors in industrial enterprises are focused on eliminating the consequences of the negative impact of internal and external threats, stabilizing the situation, protecting property and preserving the business in the short term. The necessity of developing a flexible corporate security strategy is substantiated. The application of the proposed conceptual approach to the selection and implementation of a strategy for ensuring the corporate security of industrial enterprises allows you to quickly respond to changes in the impact of major internal and external threats to adjust the implementation of the basic strategy, and helps increase the effectiveness of the implementation of protective measures.

In the future, such a system for assessing external and internal threats that affect the corporate security of industrial enterprises, will quickly and effectively form a system to counter the impact of these threats. 


\section{References}

Abalkin, L. (2019). Economic security: threats and their reflection. Economic Issues, 12, 4-13.

Anilovska, G. (2020). Calls to the army of competitors in the field of competition and market. Science newsletter NLTU of Ukraine, 23(1), 177-182.

Ansoff, H. I., Kipley, D., Lewis, A. O., Helm-Stevens, R., \& Ansoff, R. (2019). Using weak signals. In Implanting Strategic Management (pp. 449-468). Palgrave Macmillan, Cham. https://doi.org/10.1007/978-3-319-99599-1_20

Ansoff, I. (2005). Strategic management (456 p.). Economics.

Badr, Y., Biennier, F., \& Tata, S. (2011). The integration of corporate security strategies in collaborative business processes. IEEE Transactions on Services Computing, 4(3), 243-254. https://doi.org/10.1109/TSC.2010.18

Berle, A. A., \& Means, G. C. (1997). The modern corporation and private (p. 380). The MacMillan Company.

Calder, J. (2016). Corporate security in the 21st century: Theory and practice in international perspective. Security Journal, 30, 1201-1206. https://doi.org/10.1057/sj.2016.10

Chandler, A. D. (1962). Strategy and structure; chapters in the history of the history of the Industrial Enterprises (463 p.). MIT Press.

Frey, R., Rosler, L., \& Lu, D. (2019). Corporate security prices in structural credit risk models with incomplete information. Mathematical Finance, 1, 84-116. https://doi.org/10.1111/mafi.12176

Hardman, J. (2018). Three steps forward, two steps back: a view from corporate security practice of the moveable transactions (Scotland) Bill. Edinburgh Law Review, 2, 266-273. https://doi.org/10.3366/elr.2018.0485

Kryshtanovych, S., Kindzer, B., Goryn, M., Kravchenko, A., \& Frunza, S. (2020). Management of socio-economic development of tourism enterprises. Business: Theory and Practice, 21(1), 420-426. https://doi.org/10.3846/btp.2020.12162

Karloff, B. (1989). Business strategy: a guide to concepts and models. Springer.

Ludbey, C. R., Brooks, D. J., Coole, M. P. (2018). Corporate security: identifying and understanding the levels of security work in an organisation. Asian Journal of Criminology, 2, 109-128. https://doi.org/10.1007/s11417-017-9261-x

McKenzie-Skene, D. (2019). A practical guide to granting corporate security in Scotland. Edinburgh Law Review, 2, 284-285. https://doi.org/10.3366/elr.2019.0559

Mukherjee, S. (2019). Overview of the importance of corporate security in business. International Journal of Innovative Research in Science, Engineering and Technology, 8(4). https://doi.org/10.2139/ssrn.3415960

Orlyk, O. (2016). Financial and economic security strategy: the features of development and implementation. Financial And Credit Activity-Problems of Theory And Practice, 1(20), 71-83. http://apps.webofknowledge.com/full_record. do? product $=$ WOS\&search $\_$mode $=$GeneralSearch\&qid $=11 \&$

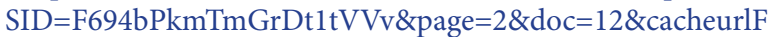
romRightClick=no
Saati, T. (2019). Decision making (Hierarchy Analysis Method). Radio and Communications, 278.

Sadok, M., Alter, S., \& Bednar, P. (2020). It is not my job: exploring the disconnect between corporate security policies and actual security practices in SMEs. Information and Computer Security (ahead-of-print). https://doi.org/10.1108/ICS-01-2019-0010

Schatz, D., \& Bashroush, R. (2018). Corporate information security investment decisions: a qualitative data analysis approach. International Journal of Enterprise Information Systems, 14(2). https://doi.org/10.4018/IJEIS.2018040101

Semenyutina, T. V. (2018). Economic risks, dangers, threats: essence and interrelation. Economic Space, 68, 106-113.

Shtangret, A. (2019). Corporate security: theoretically ambush a medical care in Ukraine. Practices of approaches to creative management of economic processes: by X International science. - Practical Conference, Vol. 1. 38-39. NAU.

Shyra, T. B. (2019). Formation and functioning of the organizational and economic mechanism for ensuring corporate security of industrial enterprises. Scientific View: Economics and Management, 3, 171-176. https://doi.org/10.32836/2521-666X/2019-65-20

Sitdikova, L., \& Starodumova, S. (2019). Corporate agreement as a means of providing security in the course of entrepreneurship development. Entrepreneurship and Sustainability Issues, 7, 324-335. https://doi.org/10.9770/jesi.2019.7.1(24)

Sylkin, O., Kryshtanovych, M., Zachepa, A., Bilous, S., \& Krasko, A. (2019). Modeling the process of applying anti-crisis management in the system of ensuring financial security of the enterprise. Business: Theory and Practice, 20, 446-455. https://doi.org/10.3846/btp.2019.41

Sylkin, O., Krystyniak, M., Pushak, Y., Ogirko O., \& Ratushniak, Y. (2019). Anti-crisis strategy in the system of ensuring financial security of the engineering enterprise: theoretical and practical aspects. 2019 IEEE International Scientific-Practical Conference Problems of Infocommunications, Science and Technology (PIC S\&T) (pp. 256-260). Kyiv, Ukraine. https://doi.org/10.1109/PICST47496.2019.9061346

Sylkin, O., Shtangret, A., Ogirko, O., \& Melnikov, A. (2018). Assessing the financial security of the engineering enterprises as preconditions of application of anti-crisis management: practical aspect. Business and Economic Horizons, 14(4), 926-940. https://doi.org/10.15208/beh.2018.63

Szczepanska-Woszczyna, K. (2018) Strategy, corporate culture, structure and operational processes as the context for the innovativeness of an organization. Foundations of Management, 10, 1. https://doi.org/10.2478/fman-2018-0004

Tulenkov, N. (2019). The key position of strategic management in the organization. Problems of Management Theory and Practice, 4, 104-107.

Zgurovsky, M. Z., \& Pankratova, N. D. (2020). Technological foresight (156 p.). Polytechnic. 